\title{
The future of education in complex systems
}

Health and education systems are increasingly recognised as complex adaptive systems, characterised by high levels of uncertainty and constant change as a result of rich, non-linear interactions that cannot all be tracked. ${ }^{[1,2]}$ This means that complex systems are inherently ambiguous and uncertain, and that they lack predictable outcomes or clear boundaries. As systems have become more complex and integrated at the beginning of the 21st century, it is no longer possible for individuals or even single disciplines to work effectively within them. ${ }^{[3]}$

The problems generated by complex systems have been called wicked problems and are not simply difficult, but impossible to solve. ${ }^{[4,5]}$ These are the kinds of problems where different stakeholders have different frameworks for even trying to describe a problem, and where the constraints and resources necessary to work on the problem change over time. ${ }^{[4]}$ They are 'messy, devious, and they fight back when you try to deal with them. ${ }^{\left[{ }^{5}\right]}$

Wicked problems are also about people, vested interests and politics, making them very subjective, which is why they do not have stable problem formulations and predefined solution concepts, and why their outcomes are unpredictable..$^{[5]}$ The uncertainty of complex systems is therefore something that we need to be comfortable with, learn to engage with, be curious about and be sceptical of. In other words, wicked problems can't be managed or studied with formal, structured methods; we must adapt to working within them. Even though we cannot solve wicked problems, we can move them forward by learning how to adapt to change, generate new knowledge, and continue to improve performance. ${ }^{[1]}$

Interprofessional education may be a possible strategy to develop the requisite competencies necessary for health practictioners to work within complex systems. These competencies include, among others, the ability to develop relationships, emotional intelligence, group work, communication and self-management, all of which are difficult to develop and assess with students. ${ }^{[6]}$

The ability to drive progress in complex systems depends on the ability to generate and connect ideas, and to implement new processes based on them. Not only do these activities take time, but they are also highly social, as success often depends on who we work with. ${ }^{[7]}$ Therefore, teams are not only important for effective work but also for the kinds of generative, creative work that 21 st-century problems require. The knowledge, skills and attributes required to work with wicked problems in complex systems are so diverse that it is impossible for a single individual or profession to make any appreciable impact. The ability to work in effective, interdisciplinary and creative teams is essential if we are to address the health problems of the future.

However, higher education is not well positioned to help students develop the competencies needed to work with wicked problems in complex social systems. Social learning theories can help practitioners to work more effectively in non-linear, dynamic systems through interprofessionalism and shared tolerance of ambiguity. ${ }^{[2]}$ However, adopting these approaches at the programme level in health professions education requires a significant change in curriculum and practice - one that traditional health and education systems are highly resistant to. ${ }^{[3]}$ If we want to make any real progress in improving health and education outcomes in an increasingly complex world, we must start taking seriously the idea that radical curriculum reform is not only indicated, but required.

\section{Michael Rowe}

Department of Physiotherapy, Faculty of Community and Health Sciences, University of the Western Cape,

Cape Town, South Africa

mrowe@uwc.ac.za

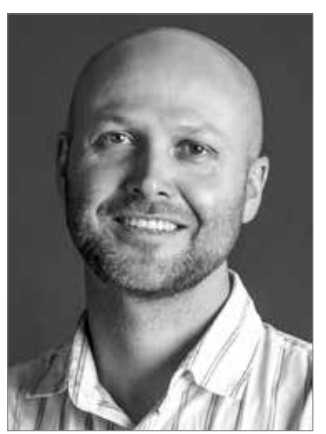

Fraser SW, Greenhalgh T. Coping with complexity: Educating for capability. BMJ 2001;323(7316):799-803. DOI: $10.1136 / \mathrm{bmj} .323 .7316 .799$

. Bleakley A. Blunting Occam's razor: Aligning medical education with studies of complexity. J Eval Clin Pract 2010;16(4):849-855. DOI:10.1111/j.1365-2753.2010.01498.x

. Frenk J, Chen L, Bhutta ZA, et al. Health professionals for a new century: Transforming education to strengthe health systems in an interdependent world. Lancet 2010;376(9756):1923-1958. DOI:10.1016/S0140-6736

4. Conklin J. Wicked problems and social complexity. CogNexus Institute. 2001. http://cognexus.org/wpf/ wickedproblems.pdf (accessed 29 September 2016).

5. Ritchey T. Wicked problems: Modelling social messes with morphological analysis. Acta Morphologica Generalis 2013:2(1):2013.

6. Knight PT, Page A. The assessment of 'wicked' competences: A report to the practice-based professional learning centre for excellence in teaching and learning in the Open University. 2007. www.open.ac.uk/cetl-workspace/ cetlcontent/.../460d21bd645f8.pdf (accessed 29 September 2016).

7. Jarche H. Valued work is not standardized. 2016. http://jarche.com/2016/09/valued-work-is-not-standardized/ (accessed 29 September 2016). 